\title{
Impact of leukoaraiosis severity on the association of outcomes of mechanical thrombectomy for acute ischemic stroke: a systematic review and a meta-analysis
}

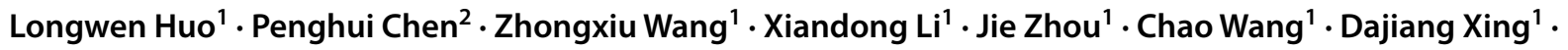 \\ Shouchun Wang ${ }^{1}$
}

Received: 8 July 2020 / Revised: 12 August 2020 / Accepted: 12 August 2020 / Published online: 28 August 2020

(c) The Author(s) 2020

\begin{abstract}
Background Leukoaraiosis (LA) severity is associated with poor outcome after mechanical thrombectomy (MT) for acute ischemic stroke (AIS) caused by large vessel occlusion. This meta-analysis aimed to assess the association of LA severity with AIS-related risk factors and outcomes of MT.

Methods PubMed, Web of Science, EMBASE, and Cochrane Collaboration Database was searched for studies on MT for AIS with LA. We conducted a random-effects meta-analysis for the prevalence of stroke risk factors and the MT outcome in the absent to moderate LA and severe LA groups.

Results We included seven cohort studies involving 1294 participants (1019 with absent to moderate LA and 275 with severe LA). The absent to moderate LA group had a significantly lower prevalence of coronary artery disease (odds ratio [OR] 0.43; 95\% CI 0.29-0.66), atrial fibrillation (OR, 0.26; 95\% CI 0.17-0.38), hypertension (OR, 0.39; 95\% CI 0.24-0.61), and ischemic stroke (OR, 0.27 ; 95\% CI 0.15-0.50) than the severe LA group. There were no significant between-group differences in symptom onset to recanalization time (364.4 versus 356.2 min, mean difference $19.4 ; 95 \% \mathrm{CI}-28.3$ to 67.2 ), final recanalization rate (modified thrombolysis in cerebral infarction score of $2 \mathrm{~b} / 3$; OR, 0.87; 95\% CI 0.55-1.38), and symptomatic intracranial hemorrhage (OR, $0.62 ; 95 \%$ CI $0.34-1.11)$. The absent to moderate LA group had a higher good functional outcome (modified Rankin Scale score of 0-2 at 90 days; OR, 4.55; 95\% CI 3.20-6.47) and a lower mortality rate (179/1019 vs 108/275; OR, 0.28; 95\% CI 0.20-0.39).

Conclusion There are unique differences in the characteristics of risk factors and clinical outcomes of ischemic stroke across patients with LA of different severity. Patients with severe LA are more likely to be associated with risk factors for cerebrovascular disease and have a poor post-MT outcome.
\end{abstract}

Keywords Leukoaraiosis $\cdot$ Thrombectomy $\cdot$ Stroke $\cdot$ Large vessel occlusion

\section{Introduction}

Electronic supplementary material The online version of this article (https://doi.org/10.1007/s00415-020-10167-0) contains supplementary material, which is available to authorized users.

Shouchun Wang

WSC@jlu.edu.cn

1 Department of Neurology and Neuroscience Center, The First Hospital of Jilin University, Changchun, China

2 Department of Cardiology, Hunan Provincial People's Hospital, The First Affiliated Hospital of Hunan Normal University, Changsha, China
Stroke is among the main mortality and disability causes with its treatment crucially relying on early revascularization and rescue ischemic penumbra. Five randomized controlled trials reported that [1] mechanical thrombectomy (MT) could improve the functional outcome after acute ischemic stroke (AIS) caused by anterior circulation large vessel occlusion (LVO). This is the highest available evidence level of a treatment technique available according to the latest guidelines from American Heart Association/ American Stroke Association (AHA/ASA) [2]. Moreover, indications for MT have been recently expanded to benefit more patients, including a longer time window [3-5], lower 
National Institutes of Health Stroke Scale (NIHSS) score [6], larger infarct cores [7], and elderly patients [8]. However, the reported rate of good post-MT functional outcome (modified Rankin Scale [mRS] score of 0-2 at 90 days) was $<50 \%$ [1]. Reported futile recanalization causes include old age, moderate and severe stroke, surgical- and instrument-related complications, delayed opening of blood vessels, distal vascular embolisms, and reocclusion [9-11]. Therefore, it is important to recognize poor outcome factors and select the most suitable patients for MT to improve the proportion of good outcomes.

Leukoaraiosis (LA) is a common neuroimaging feature of cerebral small vessel disease. On MRI, it presents as a more or less symmetrical fusion region of white matter in the left and right cerebral hemispheres, which shows hyperintensity in T2-weighted and fluid-attenuated inversion recovery images [12]. Recently, there have been increasing studies on the relationship between AIS and leukoaraiosis. Based on the association of white matter hyperintensity volumes with the 3-month functional post-stroke outcome, patients with severe LA were found to have a poor post-stroke outcome. Moreover, higher white matter hyperintensity is associated with poor improvement of the mRS score [13]. In addition, a previous systematic review and meta-analysis showed a close association of LA presence and severity with an increased risk of cerebral hemorrhage and poor functional outcome after thrombolysis for AIS [14]. Regarding endovascular therapy, there was a positive correlation of white matter hyperintensity (WMH) volumes and the risk of unfavorable functional outcome. However, there was no correlation of WMH severity with the rate of symptomatic intracerebral hemorrhage (sICH) [15]. However, studies have reported that post-MT clinical outcome is not associated with white matter burden in patients with AIS caused by LVO [16, 17]. Thus, the relationship between LA severity and the clinical outcome of MT for AIS remains unclear. This systematic review and meta-analysis aimed to improve the understanding of the clinical characteristics and thrombectomy outcome in patients with different LA severities.

\section{Methods}

\section{Searching strategy}

This systematic review and meta-analysis were based on PRISMA reports [18]. We systematically retrieved English articles from PubMed, EMBASE, Web of Science, and Cochrane library up to May 23, 2020, using the following terms as keywords or MeSH terms: white matter*, leukoaraiosis, Leukoencephalopathies, Leukoencephalopathy, Stroke, Brain Infarction, Strokes, Cerebrovascular Accident, Cerebrovascular Accidents, Cerebrovascular Apoplexy,
Cerebral Infarction, thrombectomy, Thrombectomie, Percutaneous Aspiration Thrombectomy, Aspiration Thrombectomy, Aspiration Thrombectomies, endovascular therapy, and endovascular treatment. Details regarding the search strategies are provided in the online supplementary figure 1 . Further, we conducted a manual search for the references to include published articles and pertinent reviews and ensure more comprehensive literature retrieval.

\section{Inclusion and exclusion criteria}

The inclusion criteria for studies were: (1) to evaluate observational studies in patients with AIS; (2) all patients received endovascular therapy, excluding comparisons between thrombolytic and conservative drug therapy; (3) sample size of $>50$ patients; (4) different LA severities classified according to the LA scales, including Fazekas scale [19] and Van Swieten scale [20]; (5) comparison of the clinical features and risk factors of different LA severities; and (6) reporting thrombectomy and clinical outcome of different LA severities. We excluded the following studies: (1) conference abstracts, reviews, letters, editorial, case reports, or animal studies; (2) non-comparative study or inappropriate groupings; (3) no assessment of relevant outcomes.

\section{Data extraction}

Two experienced investigators (LH, PC) independently extracted baseline data and main outcomes with any disagreements being resolved by a third investigator (ZW). We collected the following baseline data and main outcomes: demographic profiles (total number of patients, age, and sex), baseline systolic blood pressure (SBP), baseline NIHSS score, pre-existing risk factors (coronary artery disease, atrial fibrillation, hypertension, diabetes mellitus, hyperlipidemia, and ischemic stroke); stroke mechanism (large artery atherosclerosis, cardioembolic, undetermined, or others); intravenous thrombolysis; and main outcomes (symptom onset to recanalization time, successful recanalization [mTICI $2 \mathrm{~b} / 3$ ], mRS score of $0-2$ at 90 days, symptomatic intracranial hemorrhage $[\mathrm{sICH}]$, and mortality at 90 days). Moreover, we defined a van Swieten and Fazekas scale scores of 0-2 as absent to moderate LA while a van Swieten scale 3-4 and Fazekas scale 3-6 were defined as severe LA.

\section{Quality assessment}

For quality evaluation of non-randomized studies, we used the Newcastle-Ottawa Scale to evaluate the included studies. Three aspects were used to evaluate the included studies: 
election of cohorts, comparability of cohorts and assessment of outcome [21]. To assess the risk of bias, the two investigators ( $\mathrm{LH}, \mathrm{PC}$ ) conducted an independent assessment with any resulting disagreements being settled by a third investigator (XL).

\section{Statistical analysis}

We analyzed the following outcomes: demographic profiles, baseline SBP, baseline NIHSS score, pre-existing risk factors, stroke mechanism, tangible thrombolysis, and main clinical outcomes. Outcome meta-analysis was conducted using the random-effect model. We calculated the odds ratio (OR) of binary variables or the mean difference (MD) of continuous variables with the $95 \%$ confidence intervals (CIs). We evaluated inter-study heterogeneity using $I^{2}$ statistics where significant heterogeneity was defined at $P<0.10, I^{2}>50 \%$. In the case of significant heterogeneity, we conducted sensitivity and subgroup analysis to analyze the heterogeneity sources of main clinical outcomes. We performed a subgroup analysis of the LA scale scores. In the sensitivity analysis, the effect of one study on the total pooled effect size. Publication bias was assessed using funnel plots and Egger's test (significance threshold set at $P<0.10$ ). In case the single analysis included $>6$ studies, we conducted Egger's test.

Meta-analysis and statistical analysis were conducted using Stata 16.0 (StataCorp, College Station, TX, USA).

\section{Results}

\section{Search results}

Using a comprehensive search strategy, we retrieved 222 original articles. Among these articles, 39, 80, 101, and 2 were retrieved from PubMed, Web of Science, EMBASE, and Cochrane Collaboration Database, respectively. Among them, Seventy-five articles were repetitive with the remaining 147 articles being screened by the title, abstract, and full text. Finally, 7 original studies [22-28] were included, which included a prospective cohort study [28] and six retrospective cohort studies [22-27]. Figure 1 presents a flow chart of the specific study selection process.

\section{Characteristics of the eligible studies}

The included 7 cohort studies enrolled 1294 patients with AIS, including 1019 and 275 patients with absent to moderate LA and severe LA, respectively. Two and five studies were performed in China [24, 25] and The United States, respectively [22, 23, 26-28]. In addition, two studies [22, 25] used the Fazekas Scale to classify LA severity while five studies [23, 24, 26-28] used the van Swieten Scale. We used the Newcastle-Ottawa Scale to assess the risk of bias in cohort studies, including selection, comparability, and outcome biases, which indicated a low risk of bias. Table 1 shows the study characteristics of the included articles.

\section{Patient characteristics and risk factors}

According to demographic profiles, there were significant between-group differences in the age (64.6 vs. 77.3 ; mean difference, -13.57 ; $95 \% \mathrm{CI}-15.71$ to -11.43 ) and proportion of male patients $(57.3 \%$ vs. $48.4 \%$; OR, 1.55 ; $95 \%$ CI 1.09-2.19).

Regarding stroke risk factors, the absent to moderate LA group had a significantly lower prevalence of coronary artery disease $(22.6 \%$ vs. $41.0 \%$; OR, $0.43 ; 95 \%$ CI $0.29-0.66)$, atrial fibrillation ( $36.9 \%$ vs. $66.8 \%$; OR, 0.26 ; $95 \%$ CI $0.17-0.38)$, hypertension ( $66.3 \%$ vs. $83.3 \%$; OR, 0.39 ; $95 \%$ CI $0.24-0.61)$, and ischemic stroke $(11.8 \%$ vs. 29.6\%; OR, 0.27; 95\% CI 0.15-0.50) compared with the severe LA group. There were no significant between-group differences in the diabetes mellitus $(21.5 \%$ vs. $26.0 \%$; OR, 0.73 ; 95\% CI $0.49-1.09$ ), and hyperlipidemia (53.2\% vs. 59.5\%; OR, 0.79; 95\% CI 0.49-1.28). Regarding stroke mechanism, there were no significant between-group differences in large artery atherosclerosis ( $28.3 \%$ vs. $20.5 \%$; OR, 1.43 ; 95\% CI 0.87-2.36); however, there were significant differences in cardioembolic ( $48.2 \%$ vs. $73.8 \%$; OR, 0.28 ; 95\% CI 0.10-0.77). Regarding baseline SBP and baseline NHISS score, there were significant between-group differences. Table 2 shows the outcome of all the characteristics.

\section{Clinical outcomes}

There were no significant between-group differences in the symptom onset to recanalization time (364.4 vs. $356.2 \mathrm{~min}$; mean difference, $19.42 ; 95 \% \mathrm{CI}-28.35$ to 67.18$)$, the final recanalization rate (mTICI $2 \mathrm{~b} / 3 ; 82.6 \%$ vs. $85.1 \%$; OR, 0.87 ; $95 \%$ CI $0.55-1.38)$, and sICH (7.1\% vs. $11.1 \%$; OR, 0.62 ; 95\% CI 0.34-1.11). However, there was a significant between-group difference in functional independence (mRS $0-2$ at day $90 ; 51.9 \%$ vs. $19.9 \%$; OR, $4.55 ; 95 \%$ CI $3.20-6.47)$ and 90 -day mortality rates (17.6\% vs. $39.3 \%$; OR, $0.28 ; 95 \%$ CI $0.19-0.39$ ). These results are shown in Fig. 2 and Table 3.

\section{Study heterogeneity}

There was low study heterogeneity $\left(I^{2}<50 \%\right)$ as follows: age $\left(I^{2}=48.8 \%\right)$, proportion of male patients 


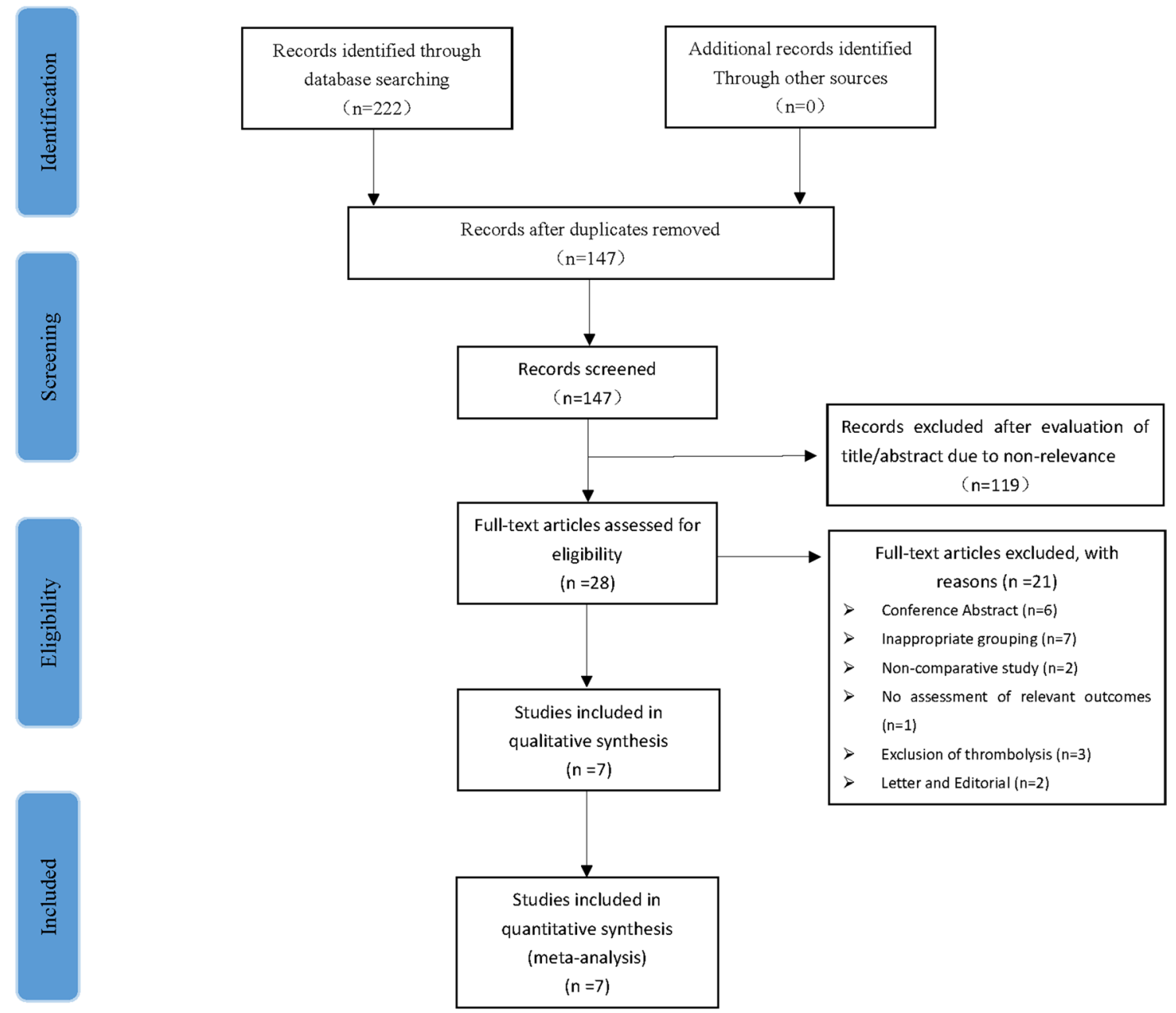

Fig. 1 Flowchart study of selection process

Table 1 Patient population and study design of included articles**

\begin{tabular}{llllllll}
\hline Author & Year & $\begin{array}{l}\text { Absent to } \\
\text { moderate LA }\end{array}$ & Severe LA & Population & Study Design & $\begin{array}{c}\text { LA Scale } \\
\text { Risk } \\
\text { of Bias } \\
\text { (NOS) }\end{array}$ \\
\hline Shi et al. & 2012 & 79 & 26 & United States & Retrospective, single-center & Fazekas Scale & 7 \\
Zhang et al. & 2014 & 100 & 29 & United States & Retrospective, single-center & van Swieten Scale & 8 \\
Guo et al. & 2019 & 213 & 38 & China & Retrospective, multicenter & van Swieten Scale & 8 \\
Liu et al. & 2019 & 43 & 54 & China & Retrospective, single-center & Fazekas Scale & 8 \\
Albo et al. & 2020 & 148 & 33 & United States & Retrospective, single-center & van Swieten Scale & 8 \\
Mikati et al. & 2020 & 122 & 22 & United States & Retrospective, single-center & van Swieten Scale & 8 \\
Mistry et al. & 2020 & 315 & 74 & United States & Prospective, multicenter & van Swieten Scale & 8 \\
\hline
\end{tabular}

$\left(I^{2}=26.5 \%\right)$, baseline SBP $\left(I^{2}=0 \%\right)$, baseline NIHSS score $\left(I^{2}=32.6 \%\right)$, coronary artery disease $\left(I^{2}=0 \%\right)$, atrial fibrillation $\left(I^{2}=17.4 \%\right)$, hypertension $\left(I^{2}=32.5 \%\right)$, diabetes mellitus $\left(I^{2}=20.8 \%\right)$, hyperlipidemia $\left(I^{2}=0 \%\right)$, large artery atherosclerosis $\left(I^{2}=0 \%\right)$, undetermined or others $\left(I^{2}=38.4 \%\right)$, final rate of mTICI $2 \mathrm{~b} / 3\left(I^{2}=0 \%\right)$, mRS score of $0-2$ at 90 days $\left(I^{2}=0 \%\right)$, symptomatic intracranial hemorrhage $\left(I^{2}=0 \%\right)$, and mortality at 
Table 2 Clinical features and risk factors of absent to moderate LA versus severe LA

\begin{tabular}{|c|c|c|c|c|c|}
\hline & $\begin{array}{l}\text { Absent to moder- } \\
\text { ate LA }(\%)\end{array}$ & Severe LA (\%) & OR $(95 \% \mathrm{CI})$ & $P$ value & $I^{2}(P$ value $)$ \\
\hline Male* & 57.3 & 48.4 & $1.546(1.089-2.194)$ & 0.015 & $26.5 \%(0.236)$ \\
\hline Coronary artery disease* & 22.6 & 41.0 & $0.434(0.286-0.659)$ & $<0.001$ & $0.0 \%(0.474)$ \\
\hline Atrial fibrillation* & 36.9 & 66.8 & $0.258(0.174-0.383)$ & $<0.001$ & $17.4 \%(0.301)$ \\
\hline Hypertension* & 66.3 & 83.3 & $0.386(0.244-0.611)$ & $<0.001$ & $32.5 \%(0.180)$ \\
\hline Diabetes mellitus & 21.5 & 26.0 & $0.729(0.486-1.093)$ & 0.126 & $20.8 \%(0.277)$ \\
\hline Hyperlipidemia & 53.2 & 59.5 & $0.788(0.486-1.278)$ & 0.334 & $0.0 \%(0.898)$ \\
\hline Ischemic stroke* & 11.8 & 29.6 & $0.272(0.148-0.501)$ & $<0.001$ & $57.6 \%(0.051)$ \\
\hline Large artery atherosclerosis & 28.3 & 20.5 & $1.432(0.869-2.358)$ & 0.159 & $0.0 \%(0.503)$ \\
\hline Cardioembolic* & 48.2 & 73.8 & $0.282(0.103-0.771)$ & 0.014 & $77.2 \%(0.004)$ \\
\hline Undetermined or others* & 23.3 & 6.6 & $3.700(1.388-9.865)$ & 0.009 & $38.4 \%(0.182)$ \\
\hline IV thrombolysis & 47.3 & 47.1 & $1.019(0.624-1.665)$ & 0.939 & $60.6 \%(0.018)$ \\
\hline \multicolumn{6}{|c|}{ Mean and mean difference $(95 \% \mathrm{CI})$} \\
\hline Age(years)* & 64.6 & 77.3 & $-13.573(-15.713$ to -11.433$)$ & $<0.001$ & $48.8 \%(0.069)$ \\
\hline Baseline SBP* & 145.3 & 152 & $-7.878(-11.635$ to -4.121$)$ & $<0.001$ & $0.0 \%(0.478)$ \\
\hline Baseline NIHSS score* & 15.9 & 17.5 & $-2.342(-3.480$ to -1.205$)$ & $<0.001$ & $32.6 \%(0.179)$ \\
\hline
\end{tabular}

$I V$ intravenous, SBP systolic pressure, NIHSS National Institutes of Health Stroke Severity Scale, OR odds ratio $* P<0.05$

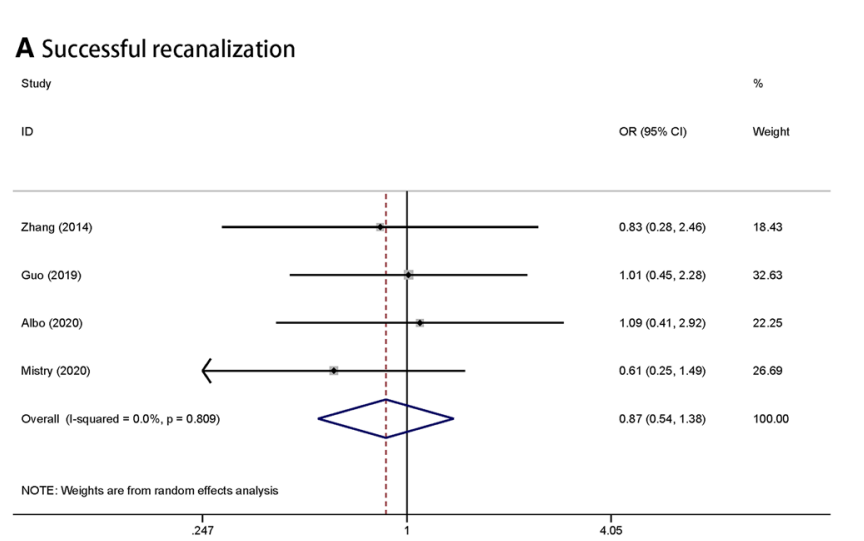

\section{B mRS 0-2 at 90 days}

Study

10

zhang (2014)

Guo (2019)

Liu (2019)

Albo (2020)

Mikati (2020)

Mistry (2020)

Overall (1-squared $=0.0 \%, p=0.982$ )

NOTE: Woights are from random offects analysis

.0499

D Mortality

Csymptomatic intracranial hemorrhage

$$
\text { Study }
$$

ID

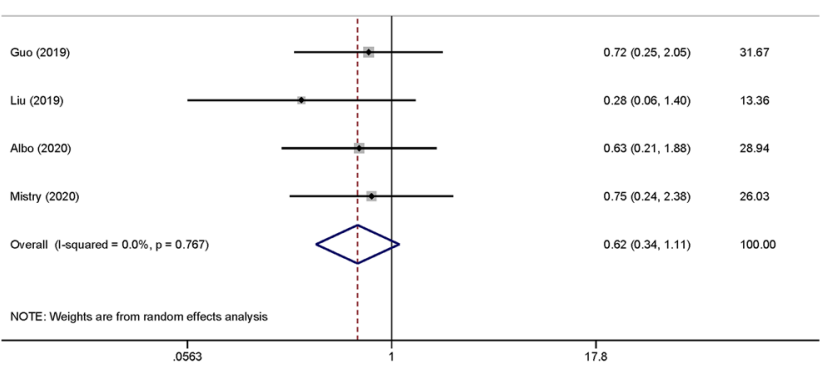

Study

ID

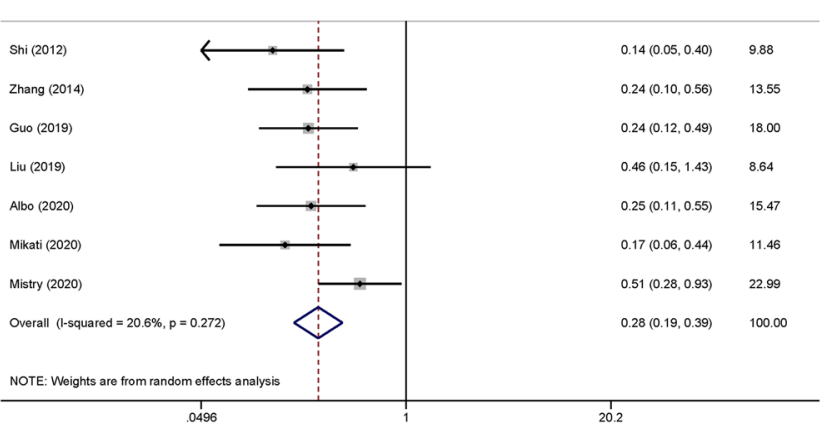

Fig. 2 a Successful recanalization, b mRS 0-2 at 90 days, $\mathbf{c}$ symptomatic intracranial hemorrhage, $\mathbf{d}$ mortality 
Table 3 Summary of meta-analysis outcomes of thrombectomy in absent to moderate LA versus severe LA

\begin{tabular}{|c|c|c|c|c|c|}
\hline & $\begin{array}{l}\text { Absent to moderate } \\
\text { LA }(\%)\end{array}$ & Severe LA (\%) & OR $(95 \% \mathrm{CI})$ & $P$ value & $\mathrm{I}^{2}$ (P Value) \\
\hline mTICI $2 b / 3$ & 82.6 & 85.1 & $0.866(0.545-1.378)$ & 0.545 & $0.0 \%(0.809)$ \\
\hline mRS score of $0-2$ at $90 \mathrm{~d}^{*}$ & 51.9 & 19.9 & $4.549(3.198-6.471)$ & $<0.001$ & $0.0 \%(0.982)$ \\
\hline $\mathrm{sICH}$ & 7.1 & 11.1 & $0.619(0.344-1.113)$ & 0.109 & $0.0 \%(0.767)$ \\
\hline Mortality at $90 \mathrm{~d}^{*}$ & 17.6 & 39.3 & $0.275(0.193-0.393)$ & $<0.001$ & $20.6 \%(0.272)$ \\
\hline \multicolumn{6}{|c|}{ Mean and mean difference $(95 \% \mathrm{CI})$} \\
\hline OTR & 364.4 & 356.2 & $19.417(-28.345$ to 67.179$)$ & 0.426 & $74.4 \%(0.004)$ \\
\hline
\end{tabular}

mTICI modified Thrombolysis in Cerebral Infarction, $m R S$ modified Rankin Scale, sICH symptomatic intracranial hemorrhage, OTR symptoms onset to recanalization time

$* P<0.05$

90 days $\left(I^{2}=20.6 \%\right)$. These results showed moderate substantial heterogeneity $\left(I^{2}>50 \%\right)$ : ischemic stroke $\left(I^{2}=57.6 \%\right)$, cardioembolic $\left(I^{2}=77.2 \%\right)$, intravenous thrombolysis $\left(I^{2}=60.6 \%\right)$, and symptom onset to recanalization time $\left(I^{2}=74.4 \%\right)$.

\section{Sensitivity analysis and publication bias}

Given the small number of included studies and low heterogeneity of clinical outcomes, we did not conduct a subgroup analysis of all studies. Regarding outcome indications for $>6$ studies, the sensitivity analysis shows that the results were statistically stable and reliable (online supplementary figure 2). Further, we used the funnel plot to qualitatively analyze the publication bias and observed possibly symmetrical distribution of these studies (online supplementary figure 3). Further, we used the Egger's test quantitative analysis of publication bias and concluded that neither mortality at 90 days $(P=0.20)$ nor functional independence $(P=0.11)$ had obvious publication bias.

\section{Discussion}

To our knowledge, this is the first systematic review and meta-analysis to investigate the effect of leukoaraiosis severity on the association of MT outcomes for AIS. Our findings suggest that patients with severe LA may be older, as well as have more relevant risk factors (e.g. coronary artery disease, atrial fibrillation, hypertension, ischemic stroke) and higher NIHSS scores. Therefore, post-MT patients may have worse functional independence and a higher mortality rate. However, the LA severity does not seem to affect the rate of successful recanalization and sICH.

There is a high LA prevalence in patients with AIS, which increases with age and is as high as $95 \%$ in people aged 60-90 years [29]. Furthermore, women tend to have greater white matter lesions than men [30], which is consistent with our findings. LA is currently considered an independent predictor of unfavorable outcome for AIS [24, 26, 31, 32]. Further, LA affects the AIS severity, including infarct volume, collateral circulation, NIHSS score, etc. Henninger et al. [33] retrospectively analyzed 117 patients with middle cerebral artery occlusion and graded LA severity using the van Swieten scale. They found an independent correlation of severe LA with infarct volume $>27 \mathrm{ml}$ where the latter was an independent predictor of unfavorable 90-day outcome. Therefore, LA severity is associated with greater infarct volume and unfavorable functional outcome. Helenius et al. [34] assessed the effect of LA severity on infarct size and NIHSS in 312 patients with supratentorial ischemic stroke by analyzing NIHSS and the diffusion-weighted imaging-defined infarct volume. Multivariable linear regression models indicated an independent association of LA and infarct volume with a larger NIHSS deficit. Similarly, we observed a positive association of the NIHSS score with LA severity. However, further studies should assess this association. Mark et al. [35] assessed the relationship between LA and collateral circulation patients with stroke with anterior circulation great vessel occlusion by performing a retrospective analysis of 178 patients with anterior circulation great vessel occlusion who were classified according to collateral grade. The Fazekas scale assesses LA severity. We observed a negative correlation of the total Fazekas score with collateral circulation; moreover, severe LA was associated with poor collateral grade among patients with AIS. Further, LA affected the short- and long-term AIS outcomes. Guo et al. [36] performed a multi-center retrospective analysis of 273 patients with acute stroke after MT and assessed early neurological improvement and deterioration according to the classification on the Van Swieten. Multivariate analysis revealed a negative correlation of severe LA with early neurological improvement. Among patients with asymptomatic intracranial hemorrhage, severe LA is an independent predictor of early neurological deterioration. Furthermore, Georgakis et al. [37] conducted a meta-analysis of the LA effects and long-term outcome in ischemic stroke. The longest follow-up time in 
the included studies was 15 years. They reported a positive association of LA severity with post-ischemic stroke dementia, dysfunction, stroke recurrence, and mortality. Similarly, this meta-analysis found similar findings of long-term AIS outcome. However, some studies have suggested that no LA effect on the AIS outcome. Atchaneeyasakul et al. [17] conducted a retrospective analysis on 56 patients to assess the association between white matter hyperintensity volume and patients with AIS undergoing MT using new-generation devices. They concluded that white matter hyperintensity volume did not affect MT outcome, including good functional, successful recanalization, mortality, and any cerebral hemorrhage.

The exact pathologic mechanism underlying the association of LA severity with unfavorable outcomes in post-MT patients with AIS remains unclear. There have been reports of an association of LA severity with older, uncontrolled hypertension and hyperhomocysteinemia, which are risk factors for unfavorable outcome in AIS [38, 39]. Regarding LA-associated mechanisms, LA has been reported to be related with microcirculation disorder, which causes small vessel narrowing, elongation, and tortuosity; moreover, this could lead to reduced cerebral blood flow [12]. Therefore, for patients with AIS, LA severity could be negatively associated with the survival rate of ischemic penumbra, which impedes good tissue outcome [40]. Second, LA is associated with platelet activation and hypercoagulability [41, 42]. Reopening of the occluded vessel reopening does not completely restore the microcirculatory blood flow of ischemic tissues [43]. Moreover, capillary contraction and perivascular astrocyte swelling aggravate the hemodynamic disorder, which leads to futile recanalization. In addition, LA severity was found to be associated with poor collateral grade in post-MT patients with AIS [44]. This indicates that patients with LA may present with damaged cerebral collateral circulation; moreover, their brain tissue may have reduced resistance to ischemia, which leads to a larger infarct core. Finally, oxidative stress, damage to the blood-brain barrier, axon and oligodendrocyte loss, and other changes are closely associated with severe LA occurrence and development, which has various effects on stroke outcome [45].

This meta-analysis has several limitations. First, there was no uniform definition for LA severity among the included studies, which affects group disagreement. Second, most of the included studies were from North America with only two coming from Asia, which increased the risk of bias. Clinical characteristics and outcomes may differ for patients in other regions, including Europe. Third, our sample size was relatively small. Finally, the included studies lacked statistical indicators of adverse outcomes, including reocclusion, sICH, parenchymal hemorrhage, etc. There is a need for future multicenter prospective cohort studies with larger sample sizes and more comprehensive outcome indicators.

\section{Conclusion}

In conclusion, for post-MT patients with AIS, preoperative CT or MRI examinations are required; however, but the LA severity is often overlooked. Patients with differences in LA severity exhibit unique risk factor characteristics. Patients with severe LA may have a lower 90-day functional outcome and higher mortality. However, it does not affect the reperfusion proportion. Thus, the presence and severity of LA should not be denied as a standard treatment for patients with AIS.

Acknowledgements We would like to thank all the study participants.

Data availability statement Not applicable.

\section{Compliance with ethical standards}

Conflicts of interest The authors have declared no conflicts of interest.

Ethical approval Ethical approval is not required.

Open Access This article is licensed under a Creative Commons Attribution 4.0 International License, which permits use, sharing, adaptation, distribution and reproduction in any medium or format, as long as you give appropriate credit to the original author(s) and the source, provide a link to the Creative Commons licence, and indicate if changes were made. The images or other third party material in this article are included in the article's Creative Commons licence, unless indicated otherwise in a credit line to the material. If material is not included in the article's Creative Commons licence and your intended use is not permitted by statutory regulation or exceeds the permitted use, you will need to obtain permission directly from the copyright holder. To view a copy of this licence, visit http://creativecommons.org/licenses/by/4.0/.

\section{References}

1. Goyal M, Menon BK, van Zwam WH, Dippel DW, Mitchell PJ, Demchuk AM, Dávalos A, Majoie CB, van der Lugt A, de Miquel MA, Donnan GA, Roos YB, Bonafe A, Jahan R, Diener HC, van den Berg LA, Levy EI, Berkhemer OA, Pereira VM, Rempel J, Millán M, Davis SM, Roy D, Thornton J, Román LS, Ribó M, Beumer D, Stouch B, Brown S, Campbell BC, van Oostenbrugge RJ, Saver JL, Hill MD, Jovin TG (2016) Endovascular thrombectomy after large-vessel ischaemic stroke: a meta-analysis of individual patient data from five randomised trials. Lancet 387:1723-1731

2. Powers WJ, Rabinstein AA, Ackerson T, Adeoye OM, Bambakidis NC, Becker K, Biller J, Brown M, Demaerschalk BM, Hoh B, Jauch EC, Kidwell CS, Leslie-Mazwi TM, Ovbiagele B, Scott PA, Sheth KN, Southerland AM, Summers DV, Tirschwell DL (2019) Guidelines for the early management of patients with acute ischemic stroke: 2019 update to the 2018 guidelines for the early management of acute ischemic stroke: a guideline for Healthcare Professionals From the American Heart Association/American Stroke Association. Stroke 50:e344-e418

3. Albers GW, Marks MP, Kemp S, Christensen S, Tsai JP, OrtegaGutierrez S, McTaggart RA, Torbey MT, Kim-Tenser M, 
Leslie-Mazwi T, Sarraj A, Kasner SE, Ansari SA, Yeatts SD, Hamilton S, Mlynash M, Heit JJ, Zaharchuk G, Kim S, Carrozzella J, Palesch YY, Demchuk AM, Bammer R, Lavori PW, Broderick JP, Lansberg MG (2018) Thrombectomy for stroke at 6 to 16 hours with selection by perfusion imaging. N Engl J Med 378:708-718

4. Desai SM, Haussen DC, Aghaebrahim A, Al-Bayati AR, Santos R, Nogueira RG, Jovin TG, Jadhav AP (2018) Thrombectomy 24 hours after stroke: beyond DAWN. J Neurointerv Surg 10:1039-1042

5. Nogueira RG, Jadhav AP, Haussen DC, Bonafe A, Budzik RF, Bhuva P, Yavagal DR, Ribo M, Cognard C, Hanel RA, Sila CA, Hassan AE, Millan M, Levy EI, Mitchell P, Chen M, English JD, Shah QA, Silver FL, Pereira VM, Mehta BP, Baxter BW, Abraham MG, Cardona P, Veznedaroglu E, Hellinger FR, Feng L, Kirmani JF, Lopes DK, Jankowitz BT, Frankel MR, Costalat V, Vora NA, Yoo AJ, Malik AM, Furlan AJ, Rubiera M, Aghaebrahim A, Olivot JM, Tekle WG, Shields R, Graves T, Lewis RJ, Smith WS, Liebeskind DS, Saver JL, Jovin TG (2018) Thrombectomy 6 to 24 hours after stroke with a mismatch between deficit and infarct. N Engl J Med 378:11-21

6. Xiong YJ, Gong JM, Zhang YC, Zhao XL, Xu SB, Pan DJ, Qu WS, Tian DS (2018) Endovascular thrombectomy versus medical treatment for large vessel occlusion stroke with mild symptoms: a meta-analysis. PLoS ONE 13:e203066

7. Yoo AJ, Berkhemer OA, Fransen PSS, van den Berg LA, Beumer D, Lingsma HF, Schonewille WJ, Sprengers MES, van den Berg $\mathrm{R}$, van Walderveen MAA, Beenen LFM, Wermer MJH, Nijeholt G, Boiten J, Jenniskens SFM, Bot JCJ, Boers AMM, Marquering HA, Roos Y, van Oostenbrugge RJ, Dippel DWJ, van der Lugt A, van Zwam WH, Majoie C (2016) Effect of baseline Alberta Stroke Program Early CT Score on safety and efficacy of intra-arterial treatment: a subgroup analysis of a randomised phase 3 trial (MR CLEAN). Lancet Neurol 15:685-694

8. Hilditch CA, Nicholson P, Murad MH, Rabinstein A, Schaafsma J, Pikula A, Krings T, Pereira VM, Agid R, Brinjikji W (2018) Endovascular management of acute stroke in the elderly: a systematic review and meta-analysis. AJNR Am J Neuroradiol 39:887-891

9. van Horn N, Kniep H, Leischner H, McDonough R, Deb-Chatterji M, Broocks G, Thomalla G, Brekenfeld C, Fiehler J, Hanning U, Flottmann F (2020) Predictors of poor clinical outcome despite complete reperfusion in acute ischemic stroke patients. J Neurointerv Surg. https://doi.org/10.1136/neurintsurg-2020-015889

10. Huang X, Cai Q, Xiao L, Gu M, Liu Y, Zhou Z, Sun W, Xu G, Liu X (2019) Influence of procedure time on outcome and hemorrhagic transformation in stroke patients undergoing thrombectomy. J Neurol 266:2560-2570

11. Seners P, Turc G, Oppenheim C, Baron JC (2015) Incidence, causes and predictors of neurological deterioration occurring within $24 \mathrm{~h}$ following acute ischaemic stroke: a systematic review with pathophysiological implications. J Neurol Neurosurg Psychiatry 86:87-94

12. Pantoni L (2010) Cerebral small vessel disease: from pathogenesis and clinical characteristics to therapeutic challenges. Lancet Neurol 9:689-701

13. Ryu WS, Woo SH, Schellingerhout D, Jang MU, Park KJ, Hong KS, Jeong SW, Na JY, Cho KH, Kim JT, Kim BJ, Han MK, Lee J, Cha JK, Kim DH, Lee SJ, Ko Y, Cho YJ, Lee BC, Yu KH, Oh MS, Park JM, Kang K, Lee KB, Park TH, Lee J, Choi HK, Lee K, Bae HJ, Kim DE (2017) Stroke outcomes are worse with larger leukoaraiosis volumes. Brain 140:158-170

14. Kongbunkiat K, Wilson D, Kasemsap N, Tiamkao S, Jichi F, Palumbo V, Hill MD, Buchan AM, Jung S, Mattle HP, Henninger N, Werring DJ (2017) Leukoaraiosis, intracerebral hemorrhage, and functional outcome after acute stroke thrombolysis. Neurology $88: 638-645$
15. Boulouis G, Bricout N, Benhassen W, Ferrigno M, Turc G, Bretzner M, Benzakoun J, Seners P, Personnic T, Legrand L, Trystram D, Rodriguez-Regent C, Charidimou A, Rost NS, Bracard S, Cordonnier C, Oppenheim C, Naggara O, Henon H (2019) White matter hyperintensity burden in patients with ischemic stroke treated with thrombectomy. Neurology 93:e1498-e1506

16. Mechtouff L, Nighoghossian N, Amaz C, Buisson M, Berthezène Y, Derex L, Ong E, Eker OF, Cho TH (2020) White matter burden does not influence the outcome of mechanical thrombectomy. J Neurol 267:618-624

17. Atchaneeyasakul K, Leslie-Mazwi T, Donahue K, Giese AK, Rost NS (2017) White matter hyperintensity volume and outcome of mechanical thrombectomy with stentriever in acute ischemic stroke. Stroke 48:2892-2894

18. Moher D, Shamseer L, Clarke M, Ghersi D, Liberati A, Petticrew M, Shekelle P, Stewart LA (2015) Preferred reporting items for systematic review and meta-analysis protocols (PRISMA-P) 2015 statement. Syst Rev 4:1

19. Fazekas F, Chawluk JB, Alavi A, Hurtig HI, Zimmerman RA (1987) MR signal abnormalities at $1.5 \mathrm{~T}$ in Alzheimer's dementia and normal aging. AJR Am J Roentgenol 149:351-356

20. van Swieten JC, Hijdra A, Koudstaal PJ, van Gijn J (1990) Grading white matter lesions on CT and MRI: a simple scale. J Neurol Neurosurg Psychiatry 53:1080-1083

21. Stang A (2010) Critical evaluation of the Newcastle-Ottawa scale for the assessment of the quality of nonrandomized studies in meta-analyses. Eur J Epidemiol 25:603-605

22. Shi ZS, Loh Y, Liebeskind DS, Saver JL, Gonzalez NR, Tateshima S, Jahan R, Feng L, Vespa PM, Starkman S, Salamon N, Villablance JP, Ali LK, Ovbiagele B, Kim D, Viñuela F, Duckwiler GR (2012) Leukoaraiosis predicts parenchymal hematoma after mechanical thrombectomy in acute ischemic stroke. Stroke 43:1806-1811

23. Zhang J, Puri AS, Khan MA, Goddeau RP Jr, Henninger N (2014) Leukoaraiosis predicts a poor 90-day outcome after endovascular stroke therapy. AJNR Am J Neuroradiol 35:2070-2075

24. Guo Y, Zi W, Wan Y, Zhang S, Sun B, Shang X, Li S, Bai Y, Li Z, Zheng D, Liu X (2019) Leukoaraiosis severity and outcomes after mechanical thrombectomy with stent-retriever devices in acute ischemic stroke. J Neurointerv Surg 11:137-140

25. Liu Y, Gong P, Sun H, Zhang S, Zhou J, Zhang Y (2019) Leukoaraiosis is associated with poor outcomes after successful recanalization for large vessel occlusion stroke. Neurol Sci 40:585-591

26. Albo Z, Marino J, Nagy M, Jayaraman DK, Azeem MU, Puri AS, Henninger N (2020) Relationship of white matter lesion severity with early and late outcomes after mechanical thrombectomy for large vessel stroke. J Neurointerv Surg. https://doi.org/10.1136/ neurintsurg-2020-015940

27. Mikati AG, Mandelbaum M, Sapnar S, Puri AS, Silver B, Goddeau RP Jr, Haussen DC, Moonis M, Jun-O'Connell AH, Henninger N (2020) Impact of leukoaraiosis severity on the association of time to successful reperfusion with 90-day functional outcome after large vessel occlusion stroke. Transl Stroke Res 11:39-49

28. Mistry EA, Mistry AM, Mehta T, Arora N, Starosciak AK, La Rosa F, Siegler JE, Kasner SE, Chitale R, Fusco M, Froehler M, Yaghi S, Schrag M, Khatri P (2020) White matter disease and outcomes of mechanical thrombectomy for acute ischemic stroke. AJNR Am J Neuroradiol 41:639-644

29. Lin Q, Huang WQ, Ma QL, Lu CX, Tong SJ, Ye JH, Lin HN, Gu L, Yi KH, Cai LL, Tzeng CM (2017) Incidence and risk factors of leukoaraiosis from 4683 hospitalized patients: A cross-sectional study. Medicine (Baltimore) 96:e7682 
30. de Leeuw FE, de Groot JC, Achten E, Oudkerk M, Ramos LM, Heijboer R, Hofman A, Jolles J, van Gijn J, Breteler MM (2001) Prevalence of cerebral white matter lesions in elderly people: a population based magnetic resonance imaging study. The Rotterdam Scan Study. J Neurol Neurosurg Psychiatry 70:9-14

31. Giralt-Steinhauer E, Medrano S, Soriano-Tárraga C, Mola-Caminal M, Rasal R, Cuadrado-Godia E, Rodríguez-Campello A, Ois A, Capellades J, Jimenez-Conde J, Roquer J (2018) Brainstem leukoaraiosis independently predicts poor outcome after ischemic stroke. Eur J Neurol 25:1086-1092

32. Jeong SH, Ahn SS, Baik M, Kim KH, Yoo J, Kim K, Lee HS, Ha J, Kim YD, Heo JH, Nam HS (2018) Impact of white matter hyperintensities on the prognosis of cryptogenic stroke patients. PLoS ONE 13:e0196014

33. Henninger N, Khan MA, Zhang J, Moonis M, Goddeau RP Jr (2014) Leukoaraiosis predicts cortical infarct volume after distal middle cerebral artery occlusion. Stroke 45:689-695

34. Helenius J, Henninger N (2015) Leukoaraiosis burden significantly modulates the association between infarct volume and National Institutes of Health Stroke Scale in Ischemic Stroke. Stroke 46:1857-1863

35. Mark I, Seyedsaadat SM, Benson JC, Kallmes DF, Rabinstein AA, Brinjikji W (2020) Leukoaraiosis and collateral blood flow in stroke patients with anterior circulation large vessel occlusion. J Neurointerv Surg. https://doi.org/10.1136/neurintsurg-2019015652

36. Guo Y, Zhang S, Li M, Sun B, Shang X, Li S, Bai Y, Li Z, Zi W, Liu X (2020) Leukoaraiosis and earlier neurological outcome after mechanical thrombectomy in acute ischemic stroke. J Neuroradiol. https://doi.org/10.1016/j.neurad.2019.10.005

37. Georgakis MK, Duering M, Wardlaw JM, Dichgans M (2019) WMH and long-term outcomes in ischemic stroke: a systematic review and meta-analysis. Neurology 92:e1298-e1308
38. Vedala K, Nagabandi AK, Looney S, Bruno A (2019) Factors associated with leukoaraiosis severity in acute stroke patients. J Stroke Cerebrovasc Dis 28:1897-1901

39. Yu L, Yang L, Li Y, Yang S, Gu H, Hu W, Gao S (2020) Hyperhomocysteinemia can predict the severity of white matter hyperintensities in elderly lacunar infarction patients. Int J Neurosci 130:231-236

40. Henninger N, Lin E, Haussen DC, Lehman LL, Takhtani D, Selim M, Moonis M (2013) Leukoaraiosis and sex predict the hyperacute ischemic core volume. Stroke 44:61-67

41. Iwamoto T, Kubo H, Takasaki M (1995) Platelet activation in the cerebral circulation in different subtypes of ischemic stroke and Binswanger's disease. Stroke 26:52-56

42. Tomimoto H, Akiguchi I, Ohtani R, Yagi H, Kanda M, Shibasaki H, Yamamoto Y (2001) The coagulation-fibrinolysis system in patients with leukoaraiosis and Binswanger disease. Arch Neurol 58:1620-1625

43. Dalkara T, Arsava EM (2012) Can restoring incomplete microcirculatory reperfusion improve stroke outcome after thrombolysis? J Cereb Blood Flow Metab 32:2091-2099

44. Giurgiutiu DV, Yoo AJ, Fitzpatrick K, Chaudhry Z, Leslie-Mazwi T, Schwamm LH, Rost NS (2015) Severity of leukoaraiosis, leptomeningeal collaterals, and clinical outcomes after intra-arterial therapy in patients with acute ischemic stroke. J Neurointerv Surg $7: 326-330$

45. Hase Y, Horsburgh K, Ihara M, Kalaria RN (2018) White matter degeneration in vascular and other ageing-related dementias. $\mathbf{J}$ Neurochem 144:617-633 